\title{
Native Hawaiians in Engineering: A Path to the Professoriate
}

\section{Dr. Thanh Truc Thi Nguyen, University of Hawai'i at Mnoa}

Nguyen is a learning technologies faculty member at the Curriculum Research \& Development Group in the College of Education, University of Hawaii at Manoa. Her work in organizational change and technology is grounded in inquiry science, communities of practice, TPACK, and most recently improvement science.

\section{Dr. Oceana Puananilei Francis, University of Hawai’i at Mnoa}

Dr. Scott F. Miller, University of Hawai'i at Mnoa

Scott Miller is an Associate Professor of Mechanical Engineering at the University of Hawaii at Manoa. His teaching and research area is in materials and manufacturing, more specifically, joining of dissimilar materials and medical device design and manufacturing.

\section{Donna Kuehu, University of Hawai'i at Mnoa}

Mr. Kapena McLean

Joshua Lelemia Irvine, University of Hawai'i at Mnoa

Mr. Joshua Lelemia Irvine is a Native Hawaiian engineer. He is pursuing a PhD in Civil and Environmental Engineering at the University of Hawaii at Manoa.

Mr. Nicholas R. Izawa 


\title{
Native Hawaiians in Engineering: A Path to the Professoriate
}

\author{
Thanh Truc T. Nguyen, Oceana Puananilei Francis, Scott F. Miller, Donna Kuehu,
} Kapena McLean, Joshua Lelemia Irvine, Nicholas R. Izawa, and Melia Iwamoto

University of Hawai'i at Mānoa

\begin{abstract}
In this paper and presentation, a research team of engineers and educators from the University of Hawai'i at Mānoa will present early findings from a three-phase, mixed-methods study where they sought to understand the gaps in progression of Native Hawaiian students to an academic career in engineering. The study is grounded in Tinto's integration framework and Bean's student attrition models, in which authors look at persistence in higher education. Tinto and Bean both suggested that students are more likely to persist in college if they are connected to both the academic as well as social life. Where both Tinto and Bean were primarily studying undergraduates, this study further explores the engineering graduate students' persistence, motivation, and the idea of connection to the Hawaiian culture. Furthermore, the study seeks to extends Bean's work regarding higher education faculty where he suggested that intrinsic factors such as being true to self and valuing of students were essential characteristics for new faculty.

One of the most underrepresented ethnic groups in engineering may be Native Hawaiians (NH). According to the 2011 US Census, the combined working population of NHs, Pacific Islanders, and 'Other Race' (grouped by U.S. Census due to small sample size) represents $4.6 \%$ of the total U.S. workforce but only $1.4 \%$ of science, technology, engineering, and mathematics (STEM) occupations. This makes NHs and Pacific Islanders the most underrepresented ethnic groups in the nation in STEM employment. Additionally, the U.S. Census national data indicates that only 700 single-race NHs or other Pacific Islanders received doctoral degree in science, engineering, and health fields in 2008.
\end{abstract}

First, selected data are shared from a 43-item undergraduate survey administered to engineering students asking about background and preparation to pursue engineering as a major $(\mathrm{N}=168)$. Barriers, support systems, financial aid, and self-perception of success between NH students $(\mathrm{n}=17)$ and non-NH students $(\mathrm{n}=151)$ differences and similarities will be discussed.

Second, major themes that emerged from structured interviews with 6 of $8 \mathrm{NH}$ engineering graduate students are presented, including a sense of belonging to their chosen major, past performance in academics, and family support, important factors for degree completion in underrepresented groups such as Hawaiians, Filipinos, African-American and Blacks Hispanics, and women in science, technology, engineering, and mathematics (STEM) fields.

Third, a short description of a six-workshop series called A'o in Engineering and research and teaching opportunities designed to support interested senior and graduate engineering students $(\mathrm{N}=20)$ will follow. 
The authors end with a proposed education model to increase $\mathrm{NH}$ career interest in the engineering professoriate.

\section{Introduction}

Native Hawaiians (NH) are significantly underrepresented and underemployed in the science, technology, engineering, and mathematics (STEM) workforce by a factor of $<3.3$. The combined working population of NHs, Pacific Islanders, and 'Other Race' (grouped by U.S. Census due to small sample size) represents $4.6 \%$ of the total U.S. workforce but only $1.4 \%$ of STEM occupations [1]. This makes NHs and Pacific Islanders the most underrepresented ethnic group in the nation in STEM employment (factor of 3.3), more so than Hispanic (2.3), African American (1.7), and American Indian and Alaskan Native (1.5) groups [1]. These statistics are of concern, especially in light of the U.S. Department of Commerce 2017 report that employment in STEM occupations grew much faster than employment in non-STEM occupations over the last decade (24.4 percent versus 4.0 percent, respectively). Furthermore, STEM occupations are projected to grow by 8.9 percent from 2014 to 2024, compared to 6.4 percent growth for nonSTEM occupations [2]. The report further found that STEM workers commanded higher wages in 2015, earning 29 percent more than their non-STEM counterparts, and that the higher earnings were seen across STEM degree holders regardless of their occupation in STEM or not.

NH underemployment in STEM fields may be directly related to the low number of NH students enrolled in STEM fields in postsecondary education, where NHs are underrepresented in general and under-enrolled in STEM fields in particular. In the state of Hawai' $i$, NHs comprise $23 \%$ of the state of Hawai' $i$ population but comprise only $14.8 \%$ of the student body and $3.8 \%$ faculty at the University of Hawai' $i$ at Mānoa (UHM) [3]. Of the 1,578 STEM faculty at UHM, there are only four NH STEM faculty members, which perhaps serves as a factor for some NH students to not pursue STEM as a major in undergraduate or graduate studies.

At the University of Hawai' $i$ at Mānoa, the flagship campus of the only public provider of higher education in Hawai' $i$, NHs constituted $14.8 \%$ of the student body as compared to their $23.1 \%$ composition of the state's college-age population (18-24 years of age) [4]. Although enrollment has increased over the past ten years and is expected to increase since NH population is expected to double in size from 2000 to 2050 [5], in 2013 NHs comprised only $10.8 \%$ of STEM enrollment. Review of actual degrees earned show the fields of study in which NH representation is lowest tend to have the highest job stability and greatest earning potential such as business administration (4.1\%), natural sciences (4\%), architecture \& engineering (3.4\%), mathematics $(3.2 \%)$, and computer science $(2.8 \%)$ [6]. NH graduation rates with a four-year degree has not significantly changed, remaining between nine and twelve percent in the past three decades [7].

In higher education, "Bridge" programs have been successful in providing greater access for research opportunities to minority graduates. The first Bridge program in 2004 was a partnership between Fisk and Vanderbilt universities to improve diversity in STEM fields, where students' persistence and passion to complete the program was considered more important than their GRE scores and GPAs [8]. As of spring 2017, the program has produced $27 \mathrm{PhD}$ graduates in physics, astronomy and materials science. Included in this number is the first African American female to graduate from the Yale astronomy program and the first African American female astronomer to 
publish a first-author Nature article [9]. Other universities have followed suit with Bridge programs of their own, including Columbia University, Ohio State University, University of South Florida, Massachusetts Institute of Technology, and University of Michigan. UHM also has a Native Hawaiian Science \& Engineering Mentorship Program (NHSEMP) summer bridge. The summer bridge program is a 10 -week summer program for incoming freshman interested in natural sciences or engineering (civil, environmental, mechanical, electrical) [10]. However, the UHM program in 2015 was not geared for graduate students nor was financial support available for graduate studies as it is for undergraduates.

Even if NH students were to enter the engineering program at UHM, there still exists the possibility of an achievement gap, which has not been studied yet at UHM. Tinto describes the achievement gap as exacerbated by financial constraints as well as prior academic preparation and educational aspirations [11]. Furthermore, students who have lower access to higher education need additional supports once they are enrolled. Tinto's research with Engstrom has shown that students who receive these institutional supports via supportive learning communities identified four factors that contributed to their success - that they had a safe place to learn, that they were in a supportive place to learn, that they were reassured that they belonged in college, and that they were encouraged to learn deeply and thereby make connections [12].

In elementary education, some research has shown that more same-race teachers in minority dominated, impoverished and underperforming schools increases academic performance and potentially pursuit of careers in that field [13]. Though no studies exist yet in higher education of same race professors and students, if this notion is extended to higher education, then it may follow that the presence of professors of same-race, minority students may increase student pursuit in that career path. The National Science Board ${ }^{14}$ reports that in 2013, 37,522 Asian or Pacific Islanders pursued a graduate degree in engineering. In their data gathering and reporting, the National Science Board was not able to report only on the Pacific Islander number [NSB report]. However, the national data indicates that only 700 single-race and 800 multi-race NHs or other Pacific Islanders received a doctoral degree in science, engineering, and health fields in 2008 (Fig.1) [15]. The number of NH principal investigators is around 30-40 for all majors [14], which is the most underrepresented ethnic group in the nation.

At UHM, the representation of self-identified NH students and faculty in Fall 2016 are small as seen in Table 1. In Fall 2016, NHs comprise only $14.8 \%(n=1,953)$ of the undergraduate student body and $14.1 \%(n=696)$ of the graduate student body [16]. Of those, 41 students were in civil engineering, 37 in electrical engineering, and 44 in mechanical engineering. In graduate studies, 2 were in civil engineering, 4 in electrical engineering, and 2 in mechanical engineering. $3.8 \%$ faculty at the UHM are NH [17]. Of the 1,578 STEM faculty at UH Mānoa, there are only four NH STEM faculty members, which comprise a fraction of one percent. Of those four, one is an engineering faculty member. Since faculty diversity has been shown to be an accurate predictor of recruitment and retention of students from underrepresented groups [18], the presence of only one engineering faculty member who is Hawaiian descent is of concern. 


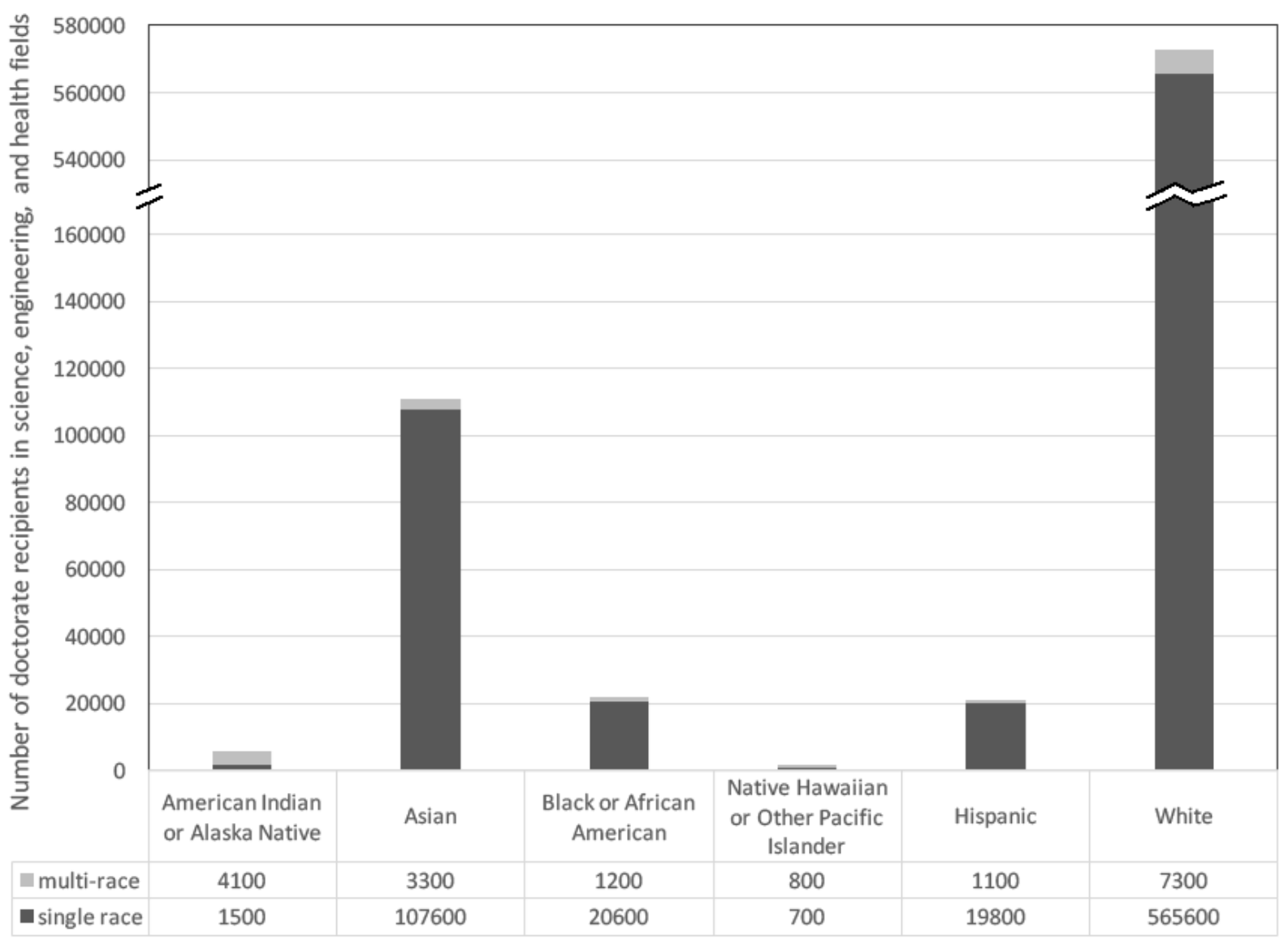

Figure 1. Single race identification among U.S. citizen and permanent resident doctorate recipients who are not of Hispanic ethnicity: 2008; Source: National Science Foundation, 2012

Table 1. Number of NH students and faculty in the University of Hawai'i at Manoa's College of Engineering, Fall 2016.

\begin{tabular}{|l|c|c|c|}
\hline \multicolumn{1}{|c|}{ Field } & Civil & Electrical & Mechanical \\
\hline Undergraduate & 41 & 37 & 44 \\
\hline Graduate & 2 & 4 & 2 \\
\hline Faculty & 1 & 0 & 0 \\
\hline
\end{tabular}

Source: UH Institutional Research Office, Fall 2016

\section{Problem Statement}

To address this concern, a team of engineering and education professors and staff sought to understand the gaps in progression of Native Hawaiian (NH) students to academic career in engineering and thus to create an education model to increase their career interest in the professoriate. The study was guided by Tinto's integration framework [19] and Bean's student attrition models [20][21], in which both authors look at persistence in higher education. Tinto and Bean both suggested that students are more likely to persist in college if they are connected to both the academic as well as social life. Where both Tinto and Bean were primarily studying 
undergraduates, this study further explores the engineering graduate student persistence, motivation, and the idea of connection to the Hawaiian culture. Furthermore, the study seeks to extends Bean's work regarding faculty [22] where he suggested that intrinsic factors such as being true to self and valuing of students were essential characteristics for new faculty.

Research on persistence of Native Hawaiian students showed that NH students had a strong selfefficacy about their ability to succeed and their intentions to complete their STEM degree. Furthermore, predicators of their self-efficacy were their belonging to a major, college GPA, family support, sense of belonging on campus, enrollment in the College of Engineering, and program participation [23]. Those who completed college were also more likely to reside on campus, engage with their peers, and engage with the faculty members [24]. Other studies showed that financial aid and parental encouragement were significant factors in degree completion as well as the science courses in high school and high school GPA [7] [25]. Additionally, prior research shed light on the need to focus on how NH conceptualize the notion of "Hawaiian" and the links between identities fostered in a culturally centered educational environment and the implications of that identity on educational and professional aspirations [26].

\section{Methodology}

In the first phase of the study, all undergraduate students in the College of Engineering at UHM were surveyed $(\mathrm{N}=168,16.1 \%$ return rate) to determine if the predictive factors in Tinto and Bean's student attrition and persistence models were present at UHM. The 43-item survey was a survey developed by engineering professors and distributed via the student engineering listservs in Spring 2015 and Fall 2016. Students were given one month in each semester to complete the voluntary survey. We then analyzed the data using simple regression models where enrollment in engineering was the dependent variable and independent variables were self reports about importance of parents' educational level, financial aid, knowledge and participation in summer bridge programs, participation in study groups, grade point average, faculty mentoring, friend supportiveness, and peer (classmates) supportiveness. Additionally, $t$-tests were conducted to see if there were any significant differences in responses from Native Hawaiian (NH) students and non-Native Hawaiian (non-NH) students. After the survey of undergraduates, interview questions were formulated from the open-ended question responses of engineering students to better understand why a student would or would not consider the professoriate [27]. In the second phase, $\mathrm{NH}$ graduate students $(\mathrm{N}=6)$ were interviewed using questions formulated from responses in the undergraduate surveys. Each $\mathrm{NH}$ graduate student was interviewed individually about career intentions and their path to the engineering studies. The interviews were transcribed and returned to the participant for member checks to help improve the internal validity of the study [28]. Though ongoing analysis is being made of the recurring patterns in the interview data [26], the first round of analysis formed the basis for topics to be addressed for the third phase of the study. The third phase was to develop support workshops for the upperclassmen and graduate students based on feedback from the interviews and literature and offer teaching opportunities for the graduate students.

\section{Data and Results}


A total of 168 undergraduate students in engineering (16.1\% return rate) completed the survey by October 17, 2016. Of the 168 students, 17 self-identified as having ancestors who are Native Hawaiian as shown in Table 2.

Table 2. Demographics of UHM Engineering students who completed the survey

\begin{tabular}{lccc}
\hline Demographic & NH Students & Non-NH Students & All \\
\hline $\begin{array}{l}\text { Native Hawaiian identifying } \\
\text { Gender }\end{array}$ & 17 & 151 & 168 \\
$\quad$ Male & 10 & 89 & 99 \\
$\quad$ Female & 7 & 61 & 68 \\
Class Level & & & \\
$\quad$ Freshman & 0 & 4 & 4 \\
$\quad$ Sophomore & 2 & 10 & 12 \\
$\quad$ Junior & 5 & 14 & 19 \\
Senior & 2 & 17 & 19 \\
$5^{\text {th }}$ Year Senior & 8 & 7 & 15 \\
Field & & & \\
$\quad$ Civil Engineering & 6 & 39 & 45 \\
Computer Engineering & 1 & 18 & 19 \\
$\quad$ Mechanical Engineering & 6 & 50 & 56 \\
Pre-Engineering & 1 & 10 & 11 \\
Biological Engineering & 0 & 0 & 0 \\
Electrical Engineering & 3 & 34 & 37 \\
\hline
\end{tabular}

As seen in Figure 2, NH students reported higher levels of importance in survey items related to completion factors except for GPA and family involvement. Of most concern was financial aid, followed by participation in summer internships, and a high GPA. Of lowest concern was friends' belief in them and information on graduate school. There was a significant difference for importance of information on graduate school, $t(167)=3.46, p<.001$ and financial aid, $t(167)=$ $2.17, p<.05$, with $\mathrm{NH}$ students reporting that those factors were more important than non-NH students. Regression analysis revealed that none of the factors predicted pursuit of engineering graduate studies or a professorial career path.

Questions on pursuit of their bachelors and pursuit of a masters, doctorate, or a career as a professor showed slight differences. Native Hawaiian students were more likely to pursue graduate education as seen in Figure 3, with a significant difference at the masters level between $\mathrm{NH}$ and non-NH students, $t(167)=2.43, p<.05$. 


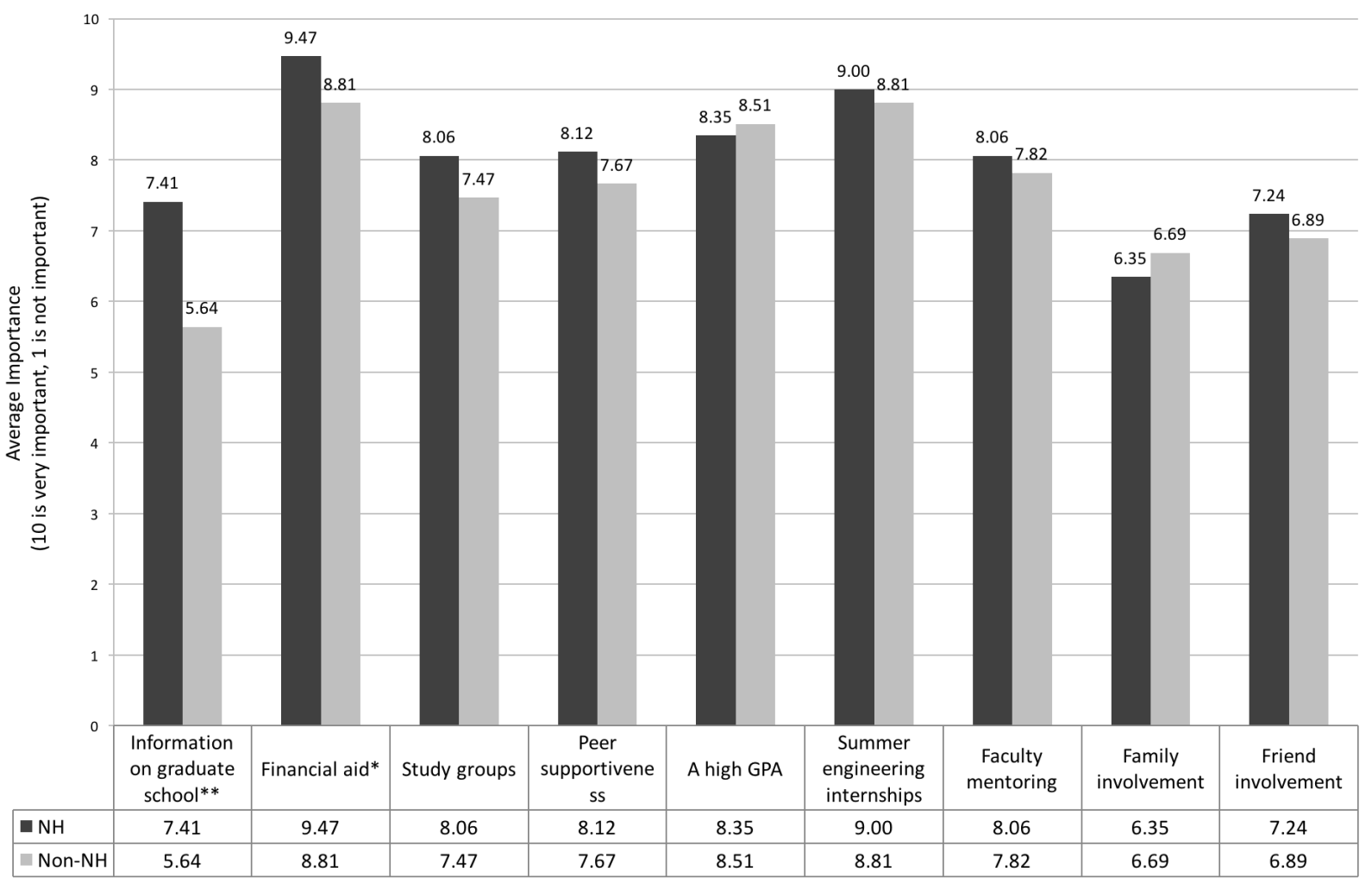

Figure 2. Important factors in completing their bachelors in engineering, $N=168$. $* p<.05, * * p<.001$

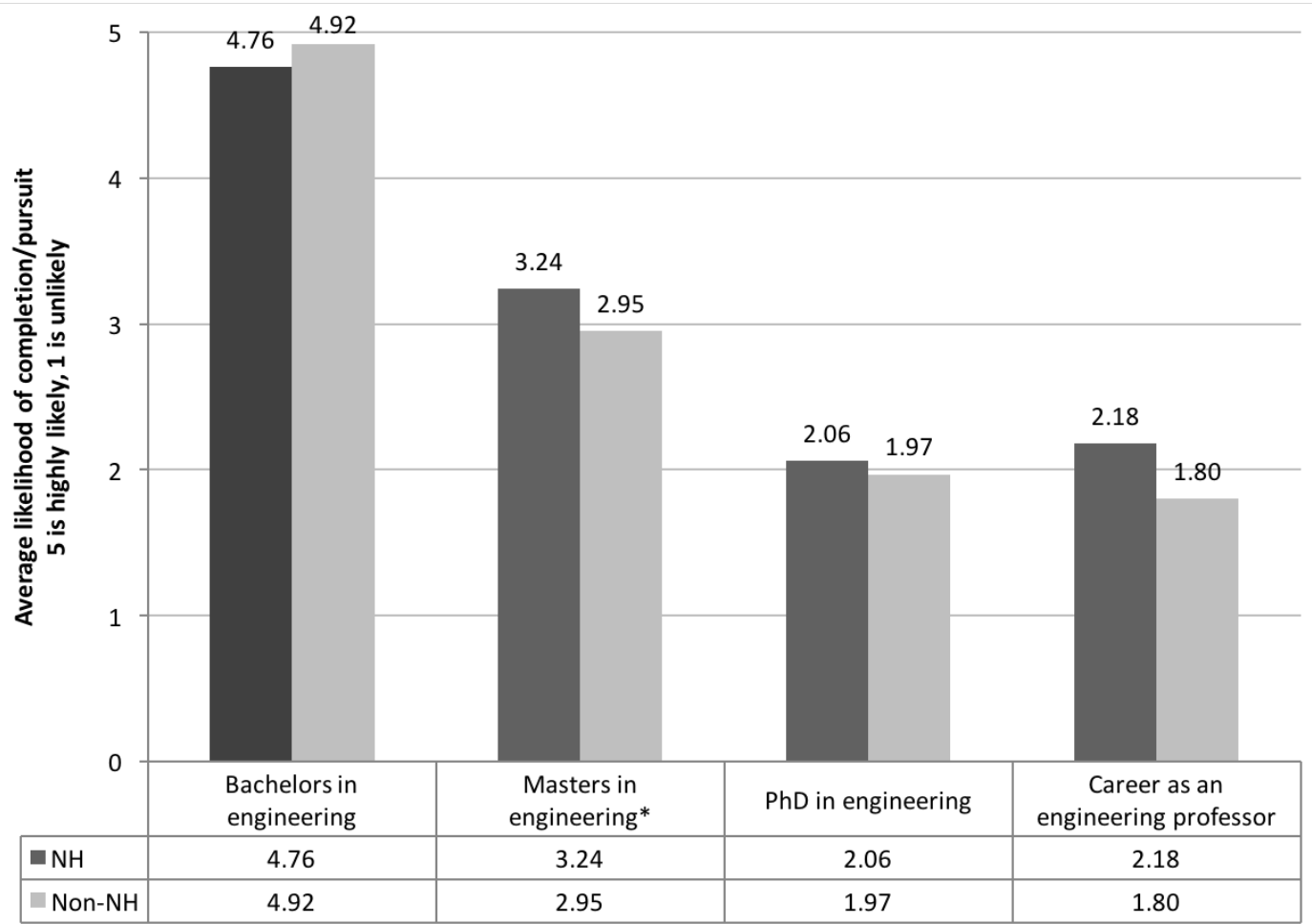

Figure 3. Likelihood of bachelors completion, pursuit of graduate degree, and professorial career, $N=168,{ }^{*} p<.05$ 
The level of education completed by parents of the engineering students was requested. Table 3 lists the level of education between the two groups. There were no notable differences in parent attainment of education.

Table 3. Highest level of education completed by parents of UHM Engineering students who completed the survey, $N=168$

\begin{tabular}{|c|c|c|c|c|}
\hline & \multicolumn{2}{|c|}{ NH } & \multicolumn{2}{|c|}{ Non-NH } \\
\hline & Mother & Father & Mother & Father \\
\hline Less than high school & $0(0 \%)$ & $0(0 \%)$ & $6(5.26 \%)$ & $12(10.5 \%)$ \\
\hline Graduated from high school & $3(27.2 \%)$ & $2(18.1 \%)$ & $23(20.1 \%)$ & $19(16.6 \%)$ \\
\hline Attended college but did not complete degree & $2(18.1 \%)$ & $1(9.09 \%)$ & $11(9.64 \%)$ & $16(14.0 \%)$ \\
\hline Completed an Associate degree (AA, AS, etc.) & $3(27.2 \%)$ & $2(18.1 \%)$ & $16(14.0 \%)$ & $16(14.0 \%)$ \\
\hline Completed a Bachelor degree (BA, BS, etc.) & $3(27.2 \%)$ & $4(36.3 \%)$ & $35(30.7 \%)$ & $32(28.0 \%)$ \\
\hline Completed a Master degree (MA, MS, etc.) & $0(0 \%)$ & $1(9.09 \%)$ & $18(15.7 \%)$ & $13(11.4 \%)$ \\
\hline $\begin{array}{l}\text { Completed a Professional or Doctoral degree } \\
\text { (JD, MD, PhD, etc.) }\end{array}$ & $0(0 \%)$ & $0(0 \%)$ & $1(0.87 \%)$ & $2(1.75 \%)$ \\
\hline Unsure or not applicable & $0(0 \%)$ & $1(9.09 \%)$ & $3(2.63 \%)$ & $3(2.63 \%)$ \\
\hline I prefer not to answer & $0(0 \%)$ & $0(0 \%)$ & $1(0.87 \%)$ & $1(0.87 \%)$ \\
\hline Total & $11(100 \%)$ & $11(100 \%)$ & $114(100 \%)$ & $114(100 \%)$ \\
\hline
\end{tabular}

Since previous research identified financial aid, summer bridge or experiential programs, reasons for pursuing engineering as factors in college persistence and success, the undergraduate survey also specifically asked questions about financial aid, summer bridge or experiential programs, reasons for pursuing engineering, and job prospects in and out of Hawai' $i$. Compared to their non-NH counterparts, survey data from the students showed that the concern about financial aid is about the same for $\mathrm{NH}$ and non-NH students (see Figure 4). Furthermore, $45.4 \%$ of the NH students participated in a summer bridge program as opposed to only $7.89 \%$ of the non-NH students. The most noteworthy difference was in the reasons student chose engineering as a career as seen in Figure 5. NH students indicated benefitting society and making a difference more than the other options of good money/high paying, wide selection of career path, and challenging work. On the other hand, non-NH student indicated that good money/high paying more than the other options.
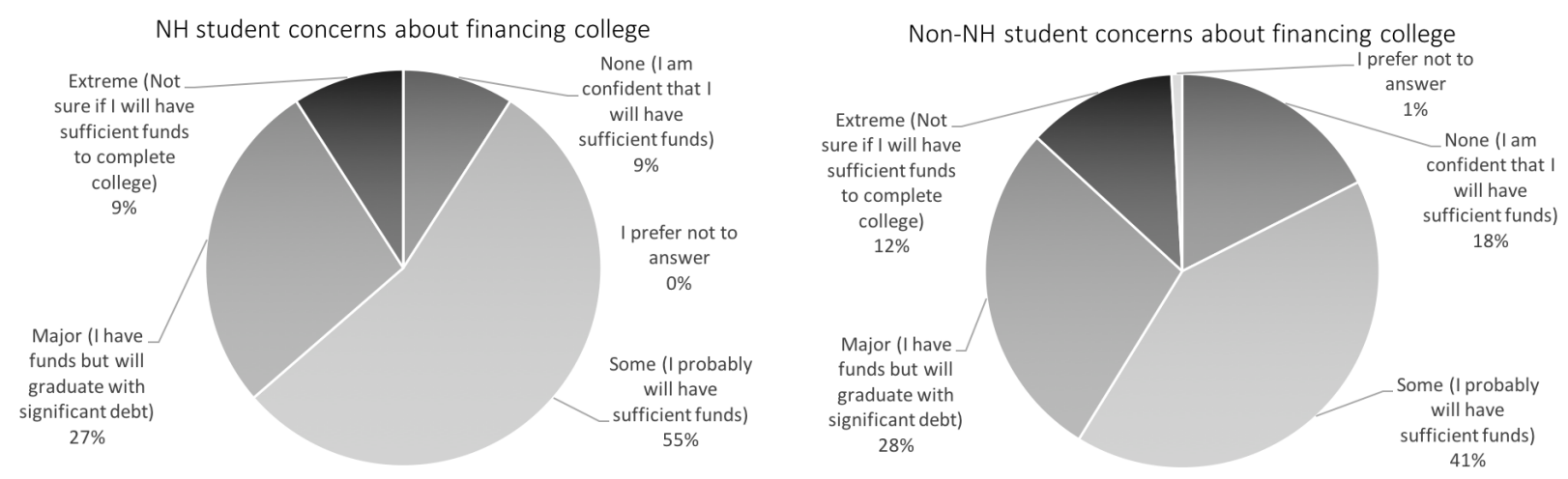

Figure 4. Concerns about financing undergraduate college degree, $N_{\mathrm{NH}}=11, N_{N_{0 n}}=114$ 

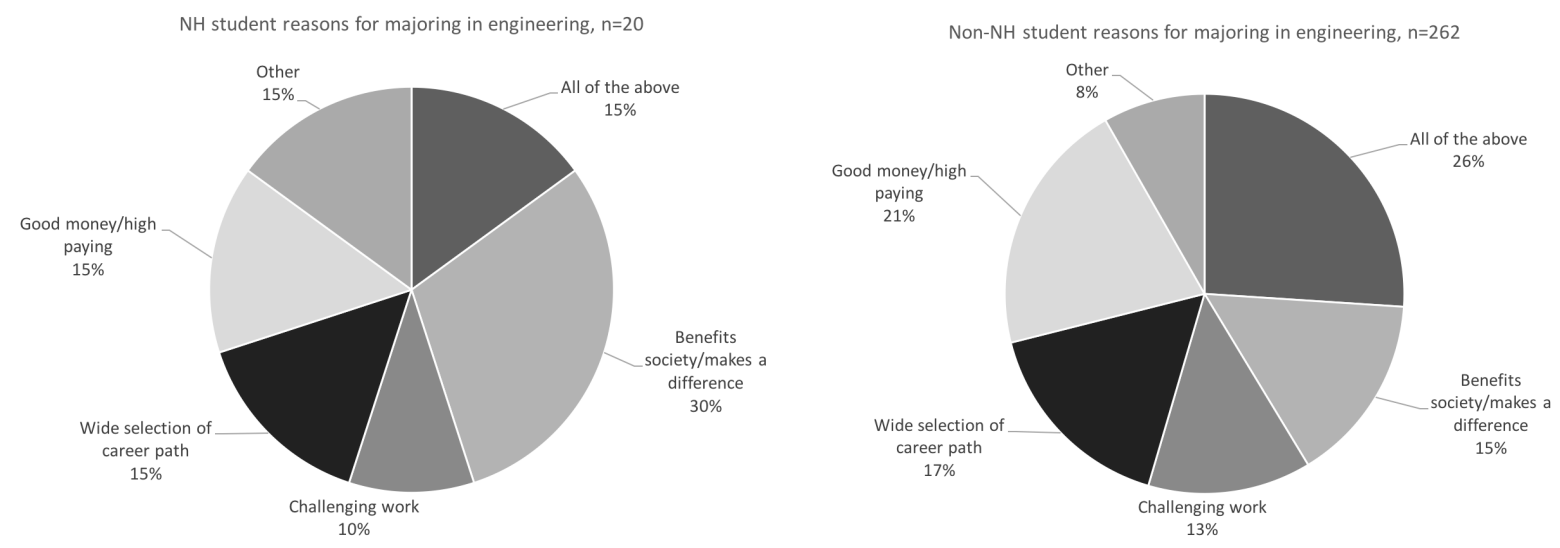

Figure 5. Reasons for majoring in engineering, $\mathbf{N}_{\mathrm{NH}}=\mathbf{2 0}, \mathbf{N}_{\mathrm{Non}}=\mathbf{2 6 2}$. Students could select more than one reason.

Of note is that the $\mathrm{NH}$ students indicated that their job intent was mostly in Hawai ' $\mathrm{i}(86 \%)$ whereas the non-NH students indicated a wider range of job prospects with $48 \%$ in Hawai' $i$, and $33 \%$ in the U.S. and 12\% in other countries (see Figure 6).
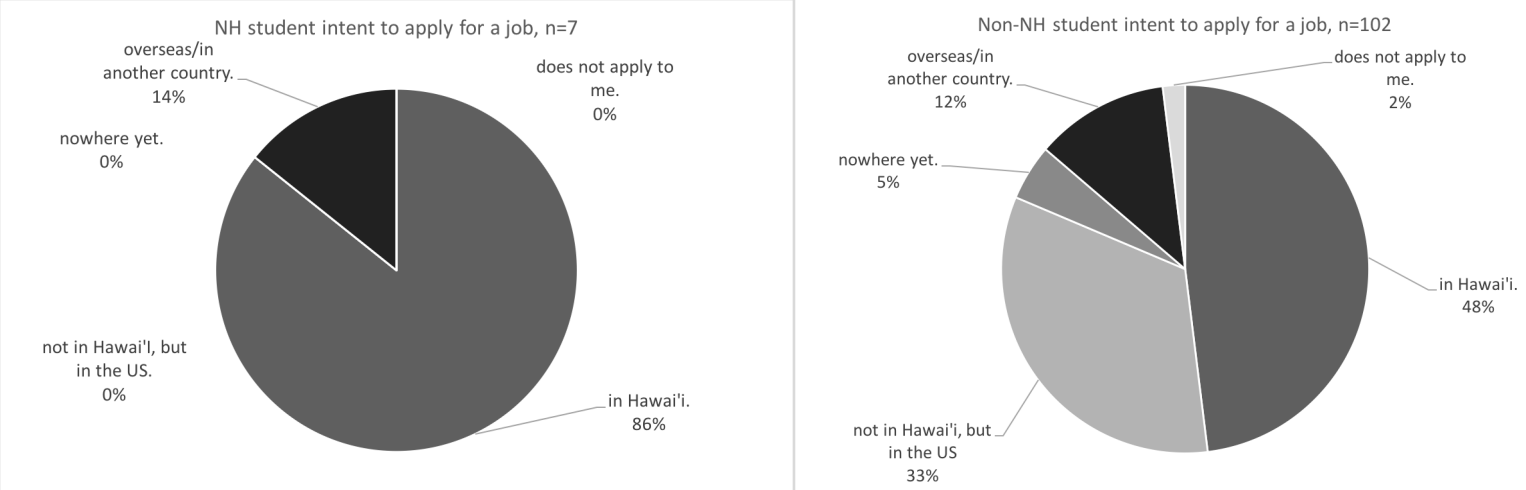

Figure 6. Job application intent, $\mathrm{N}_{\mathrm{NH}}=7, \mathrm{~N}_{\mathrm{Non}}=102$.

A total of six NH engineering graduate students volunteered to take part in the graduate student interviews. Taking into account the results from the undergraduate survey that the majority intended to stay in Hawai' $i$ and that reason for pursuit of an engineering degree was benefitting society and making a difference (rather than good money), the interviews were intended to see if these results were also reflected in the NH graduate students. Five were male and one was female. Interviews ranged from 48 minutes to 132 minutes, guided by a semi-structured interview protocol. Three candidate themes emerged from the initial coding of the data-value of family and giving back to their family; students' families low understanding of engineering and graduate education; and value of mentoring from faculty. These three themes were conveyed as having importance in some form during the interviews and formed the basis for future support sessions. The data also revealed an even stronger intent by the NH graduate students to remain in Hawai' $i$ and connect back to the communities. Interview data continues to be coded.

\section{Description of support workshops}

Six workshops were developed to address concerns of the students as identified in the interviews and from the literature. Twenty students attended the workshops, 14 of which self-identified as 
NH. Each workshop was 90-minutes long. The first two workshops connected or reconnected students with their self-identity of being Hawaiian [25] and balancing that self-identity with being a modern engineer [29], a specific request by the graduate students and also a written in response by undergraduate students. A history of Hawaiian education and ideas of stewardship and connectedness to the aina (land) and kai (ocean) were introduced and discussed in depth. Also discussed was the kuleana (responsibility) that each student felt to respect natural resources and their community, and their role in advancing Hawaiian ways of knowing into the modern engineering world. The fourth and fifth workshops focused on teaching and pedagogy where students were introduced to learning strategies like round robin, think-pair-share, know-wonderlearn, exit pass, role modeling, and popcorning. Students were also introduced to lesson plan development and encouraged to bring sample lesson plans to discuss and share for critique. In between the first set and second set of workshops were two sessions with guest speakers. The first session was with two of three Native Hawaiian professors of engineering that the research team located after surveying over seventy engineering schools in the U.S. and throughout the Pacific. These two professors shared their mo 'olelo (story) of acquiring an education and their path to the professorate. They also shared the general misconception of what it meant to them of being a professor and the lessons they have learned since then. They encouraged the graduate students to learn what research-teaching-service meant and also to understand the role of grants and research more. The second session was with two Native Hawaiian engineers who had earned PhDs, but worked in industry. In this session, students listened as the two engineers shared their very different perspectives on what it meant to be a Hawaiian engineer and their journey of self discovery and acceptance as Hawaiians that drive much of their work. Students were able to listen to the very different paths all four $\mathrm{NH}$ engineers took to their $\mathrm{PhDs}$ and how they all have given back in some way to the NH and Pacific islander student community. All four described internships and work experience as critical to their own development. All were also adamant that there was not "correct" way of being a Hawaiian engineer, but to be informed, to give back, and to uphold the rigor and quality expected an engineering doctorate were non negotiables. The six workshop titles were Connecting your mo 'olelo to a'o; Kūkā Kūkā, A'o mai and a 'o aku; Alaka' $i$ (Leadership), An Engineering Path; Hana Ka Lima: The doing of teaching; 'Ölelo no 'eau. I ka hana no a 'ike: By practice one masters the skill, and; Alaka ina a me wahi noho like o ka po 'e: Leadership and community. Two teaching opportunities in undergraduate engineering courses for each graduate student were developed. Workshop evaluation is still ongoing as of this writing.

\section{Description of teaching opportunities for graduate students}

Opportunities were also developed for the NH graduate students to teach undergraduate and precollege science, engineering, mathematics, and technology students. Exposure to teaching and mentorship was considered important to encourage NH graduate students to consider a career as a professor. In our interviews, we found that the graduate students were mostly involved in outreach events like career fairs and guest speaking engagements in middle and high school classrooms. Additionally, though teaching assistants in courses, they generally graded papers and organized study groups. The graduate students were asked to identify which engineering subject they were comfortable in teaching, then engineering professors served as mentors to the $\mathrm{NH}$ graduate students in lecturing and preparing engineering material for the undergraduate engineering classroom. The result was two teaching experiences for each NH graduate student in 
a core engineering class offered by University of Hawai'i, i.e. Fluid Mechanics Fundamentals, which is also a writing intensive course. The NH graduate students taught a class size of 39 students and both Powerpoint and Blackboard were used for instruction. The process of preparation included the professor providing preliminary lecture notes and sample problems to $\mathrm{NH}$ graduate students; the NH graduate students preparing their own lecture notes to present in class; the NH graduate students lecturing in class, which included presenting new theories and concepts and working problems on the board, and; the class evaluating the NH students' performance through a faculty-student evaluation form, i.e. an official form that students usually fill out to evaluate faculty at UH at the end of a semester. The results of those course feedback forms are not part of this study nor are they yet available to the UH graduate students and mentor professors.

\section{Discussion}

From the study, a preliminary idea of an education model to increase NH career interest in the engineering professoriate emerges, one that takes into account the importance of connectedness to the community and self-identity as a Native Hawaiian as not needing to exist in binary to being an engineer. At the undergraduate level, opportunities to discuss financing advanced studies and having role models to discuss graduate school are important. At the graduate level, providing space for students to feel connected to their Hawaiian community is critical along with mentorship by professors. Additionally, providing constant internship and post-doc information could be important factors.

From the undergraduate surveys, the NH undergraduate students indicated more concern about financial aid and information about additional graduate studies than their counterparts, which is supports the notions presented by Tinto [11] and Bean [21] in their work on student persistence. Additionally, NH students are more likely to pursue an advanced degree and have strong beliefs in their likelihood to complete their degrees and possibility of pursuing an advanced degree, which extends the notion that Kaakua [23] put forward that NH self-efficacy in higher education being related to their family support and intentions to persist. The data suggests that the actual pursuit of those advanced degrees may be influenced by information available about those degrees as well as the financial aid available to NH students. The financial aid challenge was also mentioned by all the interviewed graduate students, a theme that continued from undergraduate results. In previous studies, financial aid was seen as a predictive factor in pursuit of school and continued pursuit of a graduate degree. Though this study did not delve deeply into financial aid or student records, the study team did find students who experienced problems with stipends as Pell or non-Pell grants as Hokoana [23] had found in his study.

When in graduate school, the NH students in this study spoke of giving back to the family and community even if their families did not fully understand their pursuit of an engineering graduate degree. This finding of community connectedness was also reflected in the undergraduate survey where $\mathrm{NH}$ undergraduates indicated that giving back to society was a major driver for pursuing engineering and that they were looking mostly in Hawai' $i$ for jobs. During an interview, one student described his desire to stay in Hawai' $i$ and remain firmly anchored to the islands.

However, what concerned him most about the academic pathway was the academic culture and to balance kuleana (responsibility) with the lähui (Hawaiian people) and 'ohana (family). With 
the rigorous demands of the professoriate and the deep sense of kuleana as a Hawaiian, he continued to struggle to see both coexisting. Another student shared that the academic pathway for an indigenous student in STEM is a continual process of self-identification, requiring reconciliation of the native culture in which they were born, and a modern society they strive to excel in while guarding against having to compromise values along the way in order to participate. The presentations by the four $\mathrm{NH}$ engineering $\mathrm{PhD}$ guest speakers also echoed the sentiments by the students. Graduate programs should make space for these kinds of conversations and concerns to be voiced by students, whether minority or underrepresented or not.

Mentorship was spoken of as an important part of Native Hawaiian success and belief in their own place in graduate studies. The NH students described that mentorship was a cornerstone of traditional Hawaiian education, where children learned at the feet of kumu (teachers) and young men and women honed their craft alongside their kupuna (elders) [23]. Children depended on their makua (parents) and their kumu to encourage them to pursue a particular role in society. In the same way, some NH engineering graduate students did not see themselves as future professors until a professor in this study encouraged them to consider it. The workshops were designed to address mentorship [30] between graduate students and faculty. Extending Ahn and Cox's work in undergraduate mentorship [31], our workshops and teaching opportunities aimed build a positive working relationship with graduate students in a research and teaching setting, recognizing student needs and personalizing the mentoring approach. This intervention explicated discussing how the role of a mentor may have positive impact on preparing graduate students for the tripartite role of professors, i.e. research, teaching, and service.

The authors caution that the findings of this study, because of the small sample size, should not be generalized to other populations. The statistics of enrollment and percentage of Hawaiians in the general or student populations should not be applied to other institutions. However, it is suggested that all STEM fields in higher education consider the importance of cultural and social capital as they support their underrepresented students [32] [33] [34]. Other research has shown that students sometimes may fear the need to choose to succeed in school over their need to identify with their own culture, also known as oppositional culture theory [35]. Additionally, the teaching evaluation course surveys, designed by the institution and not specifically for their different teaching strategies, may not be as reflective of effective teaching on their part. Connecting their self-identity with that of the profession of engineering [36] is a critical step in assisting students not only pursue graduate education, but consider themselves as good mentors and possibly professors [37] for the next generation [38]. Furthermore, the authors recommend discussing with students of indigenous communities the different and many paths to what we consider scientific or technical knowledge, and that many non-western methods are no less scientific [39].

Last, but of serious concern, is the ability of the NH graduate students, once they earn their PhDs and perhaps complete a post doc, to be hired into tenure-track professor positions in Hawai'i at the only research very high university if they earned their degree from the same institution. Being strongly connected to their community and having financial aid concerns that contribute towards staying here in Hawai' $\mathrm{i}$, perhaps encouraging the $\mathrm{NH}$ graduate students to pursue the professoriate in Hawai' $i$ is not yet possible, at least at the University of Hawai' $i$ at Mānoa. 
Conversations need to take place about hiring practices and academic mobility. As the authors continue to develop a model for NH engineers to become NH engineering professors, discussion could start about partnerships between universities where graduate students can do expanded studies or post docs.

The authors posit that what is learned in engineering education for Native Hawaiians will be enlightening for other Pacific and indigenous cultures around the world. These voices belong in the present and future society, from medicine to law to farming to engineering to education to politics and more. In contributing in industry and innovation, the ways of the past can be honored, yet can also be advanced into the modern world. However, a very purposeful investment into these Pacific Island students is needed.

\section{References}

[1] L. C. Landivar, "Disparities in STEM Employment by Sex, Race, and Hispanic Origin: American Community Survey Reports," United States Census Bureau, September 2013. [Online]. Available: https://www.census.gov/prod/2013pubs/acs-24.pdf. [Accessed: October 2, 2016].

[2] United States Department of Commerce, Economics \& Statistics Administration, STEM Jobs: 2017 Update. Washington, DC: ESA; 2017. [Online]. Available: http://www.esa.doc.gov/reports/stem-jobs-2017-update. [Accessed: November 18, 2017].

[3] University of Hawaii Institutional Research Office, "Hawaiian Student Headcount Enrollment by College and Major," University of Hawai“i, 2010. [Online]. Available: http://manoa.hawaii.edu/ovcaa/mir/?page=fac_enr. [Accessed: November 17, 2017].

[4] P. Hsu and and J. Nielson, "Population update 2010: The R\&E annual update series," Kamehameha Schools Research \& Evaluation, 2010. [Online]. Available: http://www.ksbe.edu/_assets/spi/pdfs/annual_updates/population_report_2010.pdf [Accessed: November 17, 2017].

[5] S. Kana'iaupuni, N. Malone, \& K. Ishibashi, Ka huaka'i: 2005 Native Hawaiian education assessment. Honolulu, HI: Kamehameha Schools, Pauahi Publications, 2005.

[6] University of Hawaii. Degrees and certificates earned. Honolulu, HI: University of Hawaii, 1997 to 2001.

[7] D. H. K. Matsumoto, "Factors affecting native Hawaiian student persistence in education," Ed.D. dDissertation, School of Education, Univ. of Southern California, CA, 2010.

[8] S. Haruch, "A graduate program works to diversify the science world," Code-Switch, National Public Radio, 13-Jan-2014. [Online]. Available: https://www.npr.org/sections/codeswitch/2013/12/17/251957062/a-graduate-programworks-to-diversify-the-science-world. [Accessed: November 17, 2017].

[9] "About the Bridge Program," Fisk-Vanderbilt Bridge Program. [Online]. Available: http://fisk-vanderbilt-bridge.org/program/description/. [Accessed: November 17, 2017].

[10] "Freshman Bridge Program at UH Manoa," Native Hawaiian Science \& Engineering Mentorship Program, University of Hawai'i, 2009. [Online]. Available: http://nhsemp.eng.hawaii.edu/sbridge-uh.html. [Accessed November 17, 2017].

[11] V. Tinto, "Moving beyond access: Closing the achievement gap in higher education." in Achievement Gap Initiative, 2005, Cambridge, MA [Online]. Syracuse, NY: Syracuse 
University, 2005. Available: https://vtinto.expressions.syr.edu/wpcontent/uploads/2013/01/Harvard-2005-Speech.pdf. [Accessed: March 21, 2017].

[12] C. Engstrom and V. Tinto, "Access without support is not opportunity," Change: The Magazine of Higher Learning, vol. 40, no. 1, pp. 46-50, 2008.

[13] T. S. Dee, "The race connection: Are teachers more effective with students who share their ethnicity?," Educ. Next, vol. 4, no. 2, p. 52-60, Mar. 2004.

[14] National Science Board, "Science and Engineering Indicators 2016". Arlington, VA: National Science Foundation (NSB-2016-1), 2016. [Online]. Available http://www.nsf.gov/statistics/2016/nsb20161/ [Accessed: November 17, 2017].

[15] L. M. Milian and T. B. Hoffer, "Racial and Ethnic Diversity among U.S.-Educated Science, Engineering, and Health Doctorate Recipients: Methods of Reporting Diversity," National Science Foundation, 2012. [Online]. Available: http://www.nsf.gov/statistics/infbrief/nsf12304/ [Accessed: November 17, 2017].

[16] University of Hawaii, "Common Data Set 2016-2017," University of Hawaii, 2017. [Online]. Available: http://manoa.hawaii.edu/miro/wpcontent/uploads/2014/06/CDS_2016-2017_2016_10_17.pdf. [Accessed: November 18, 2017].

[17] University of Hawaii Institutional Research Office. "Hawaiian Student Headcount Enrollment by College and Major," University of Hawaii Institutional Research Office, 2010. Available: http://manoa.hawaii.edu/ovcaa/mir/?page=fac_enr. [Accessed: November 17, 2017].

[18] C. B. Leggon. "Diversifying science and engineering faculties: Intersections of race ethnicity and gender," American Behavioral Scientist. vol. 53, no. 7, pp. 1013-1028, February 2010.

[19] V. Tinto, Leaving college: Rethinking the causes and cures of student attrition, 2nd Edition. Chicago, IL: University of Chicago Press, 1993.

[20] J. P. Bean. "Dropouts and turnovers: The synthesis and test of a causal model of student attrition," Research in Higher Education, vol. 12, no. 2, pp. 155-187, April 1980.

[21] J. P. Bean. "Student attrition, intentions, and confidence: Interaction effects in a path model," Research in Higher Education, vol. 17, no. 4, pp. 291-320, May 1982.

[22] J.P. Bean. "Alternative Models of Professorial Roles: New Languages to Reimagine Faculty Work," The Journal of Higher Education, vol. 69, no.5, pp. 496-512, September/October 1998.

[23] J. K. Kaakua, "Self-efficacy beliefs and intentions to persist of native Hawaiian and nonHawaiian science, technology, engineering, and mathematics majors," Ed.D. dissertation, School of Education, Univ. of Southern California, CA, 2014.

[24] L. K. Hokoana, "Native Hawaiians and college success. Does culture matter?," Ed.D. dissertation, School of Education, Univ. of Southern California, CA, 2010.

[25] J. A. K. Oliveira, "Native Hawaiians' success in higher education: Predictive factors and bachelor's degree completion," Ed.D. Dissertation, School of Education, Univ. of Southern California, CA, 2005.

[26] E. K. Wright, "Education for the nation: Forging indigenous Hawaiian identity in higher education," Ph.D. Dissertation, College of Education, Univ. of California Los Angeles, CA, 2003.

[27] S. B. Merriam. Qualitative Research and Case Study Applications in Education. San Francisco, CA: Jossey-Bass Publishers, 1998. 
[28] Y.S. Lincoln, YS. and E.G. Guba. Naturalistic Inquiry. Newbury Park, CA: Sage Publications, 1985.

[29] G. Snively and J. Corsiglia, J. "Discovering indigenous science: Implications for science education," Science Education, vol. 85, pp.6-34, 2000.

[30] C. Pfund, C. M. Pribbenow, J. Branchaw, S. M. Lauffer, and J. Handelsman, (2006) "The Merits of Training Mentors," Science, vol. 311, no. 5760, pp. 473-474, 2006.

[31] B. Ahn and M. F. Cox. "Knowledge, skills and attributes of graduate student and postdoctoral mentors in undergraduate research settings," Journal of Engineering Education, vol. 105, no. 4, pp. 605-629, 2016.

[32] E. W. Gordon, Supplementary education: The hidden curriculum of high academic achievement. Lanham: Rowman \& Littlefield Publishers, 2005.

[33] S. Malcom and M. Feder. "Instructional Practices, Departmental Leadership, and Cocurricular Supports," in Barrier and opportunities for 2-year and 4-year STEM degrees: Systemic change to support students' diverse pathways. S. Malcom and M. Feder, Eds. Washington, DC: National Academies of Sciences, Engineering, and Medicine, National Academies Press, 2016, pp. 83-102.

[34] C. Sonn, B. Bishop, \& R. Humphries, "Encounters with the dominant culture: Voices of indigenous students in mainstream higher education," Australian Psychologist, vol. 35, no. 2, pp. 128-135, 2000.

[35] J. U. Ogbu and H. D. Simons, "Voluntary and involuntary minorities: A cultural-ecological theory of School Performance with Some Implications for Education," Anthropol. Educ. Q., vol. 29, no. 2, pp. 155-188, 1998.

[36] H. M. Matusovich, R. A. Streveler, \& R. L. Miller, "Why do students choose engineering? A qualitative, longitudinal investigation of students' motivational values," Journal of Engineering Education, vol. 99, no. 4, pp. 289-303, 2010.

[37] E. Bardon, "Career goals and decisions: An intersectionality approach," M.A. thesis, Univ. of Toronto, Toronto, ON, Canada, 2013.

[38] T. Goldfinch, C. Layton, \& T. McCarthy, "Encouraging Cultural Awareness in Engineering Students," in 21st Annual Conference for the Australasian Association for Engineering Education, 2010, Sydney, Australia [Online]. Sydney, N.S.W.: Engineers, Australia, 2010. Availability: http://ro.uow.edu.au/cgi/viewcontent.cgi?article=7219\&context=engpapers. [Accessed: March 21, 2017].

[39] D. Turnbull, Masons, Tricksters, and Cartographers: Comparative Studies in the Sociology of Scientific and Indigenous Knowledge, Richland, MO: Taylor \& Francis, 2003. [Online] Available:

https://books.google.com/books?id=zqrPhJk09moC\&dq=Masons, +Tricksters, +and+Cartog raphers:+Comparative + Studies + in + the + Sociology + of + Scientific + and + Indigenous + Knowle dge\&lr=\&source=gbs_navlinks_s. [Accessed: July 13, 2017]. 